\title{
Novel epoxy-benzoxazine water-based emulsions with reactive benzoxazine surfactants for coatings
}

\author{
R. Ambrožič, U. Šebenik, M. Krajnc* \\ University of Ljubljana, Faculty of Chemistry and Chemical Technology, Aškerčeva cesta 5, 1000 Ljubljana, Slovenia
}

Received 2 March 2014; accepted in revised form 18 April 2014

\begin{abstract}
Novel epoxy-benzoxazine emulsions designed for water-based coatings were prepared and investigated. Bisphenol A-based epoxy resins with molar weights of 340,377 and $1750 \mathrm{~g} / \mathrm{mol}$ along with epoxidized soybean oil were emulsified using mono- and bi-functional benzoxazine surfactants, which are able to react with epoxy resins at their cure temperature. The structure of synthesized surfactants carrying one or two polyether chains was confirmed using Fourier transform infrared spectroscopy, ${ }^{1} \mathrm{H}$ nuclear magnetic resonance and differential scanning calorimetry. Stability of emulsions was verified by particle diameters measurements. Coatings, made directly from emulsions, were dried and cured at elevated temperature using 3,3'-dimetoxybenzidine as curing agent to ensure a highly cross-linked structure of thermosetting films. Curing process, thermal properties and hardness of cured films were investigated. It was found that benzoxazine molecules were well incorporated into the epoxy network upon curing, which ensures no void structure of cured copolymer and enhanced coating properties.
\end{abstract}

Keywords: thermosetting resins, epoxy resins, benzoxazine, emulsions, coatings

\section{Introduction}

Benzoxazine resins are a novel class of thermosetting phenolic resins, which can be synthesized from raw materials, such as phenols, formaldehyde and primary amines. Holly and Cope [1] were the first who reported the synthesis of benzoxazine in 1944. The polymerization and curing process of a benzoxazine compound is subjected to thermally accelerated, cationic ring-opening polymerization with or without an added initiator [2]. Benzoxazine polymerization is autocatalyzed as the newly produced phenolic structure, generated with ring opening mechanism, acts as an initiator and catalyst [2-5]. No by-products are formed during the curing process, resulting in no void in the final structure. Polybenzoxazines have excellent mechanical properties such as high modulus, high strength and high glass transition temperature $\left(T_{\mathrm{g}}\right)$, which is usually higher than their curing temperature. This, in combination with other advantages, such as high char yield, storage stability of the resins at room temperature, low heat release, near-zero shrinkage during curing, superior FST (fire, smoke, toxicity) properties and low water uptake, make polybenzoxazines very promising materials for future applications [2, 4-7]. Moreover, the versatile chemistry of benzoxazines offers the possibility of designing benzoxazine molecules with novel and/or specific properties, which give applicative functions. Designed properties of benzoxazine molecules may be achieved by a proper selection of phenol and amine compounds for the synthesis.

The polymerization and curing temperature of benzoxazine resins, which usually take place in temperature range between 140 and $220^{\circ} \mathrm{C}$, may be higher than desirable for some industrial applications.

\footnotetext{
${ }^{*}$ Corresponding author, e-mail: matjaz.krajnc@fkkt.uni-lj.si

(C) BME-PT
} 
Their low cross-linking density, which is surprisingly low considering their high stiffness and $T_{\mathrm{g}}$ compared with other thermosets, is an additional problem. The main reason for high stiffness is the presence of strong $\mathrm{H}$-bonds between polybenzoxazine molecules. Therefore, to further improve material properties a number of studies are directed toward reducing the curing temperature of benzoxazine, finding new low-temperature curing catalysts and increasing the cross-linking density of polybenzoxazine material $[3,5,6,8,9]$.

A promising way to achieve a higher cross-linking density is the incorporation of epoxy resins into the benzoxazine matrix $[8,10,11]$, because the ringopening polymerization of a benzoxazine produces phenolic groups, which can react with epoxy compounds. Unfortunately, also copolymerization of benzoxazines with epoxy resins takes place at elevated temperatures $[8,10-18]$. However, combining epoxy and benzoxazine resins seems a very perspective approach to design thermosets of enhanced properties, since also epoxy resins possess some excellent properties, such as good chemical resistance to solvents and good adhesion to many substrates $[8,11$, $18,19]$. One of promising applications may be an epoxy-benzoxazine coating for different substrates. Due to environmental and economic concerns waterbased emulsions to organic solvent-based polymer solutions are preferred in coating industries. The main drawback of an emulsion coating system is the presence of a non-polymerizable surfactant in its formulation, which reduces coating's cross-linking density, film hardness and weakens its corrosion protection function. By applying a benzoxazine molecule, which acts as reactive surfactant in an epoxy water-based emulsion, this problem could be overcome. Moreover, such approach may offer the possibility of preparing novel blends from epoxy resins and to them incompatible polymers in emulsions, where benzoxazine surfactant would acts as compatibilizer as well. Sawaryn et al. [20, 21] have already designed benzoxazine surfactants. They confirmed that benzoxazine surfactants could stabilize benzoxazine miniemulsions.

The aim of the work presented in this article was to apply reactive benzoxazine surfactants in epoxy emulsions. The surfactants should be able to stabilize oil in water $(\mathrm{o} / \mathrm{w})$ epoxy emulsions and should be capable of crosslinking with epoxy resins and therefore become part of cured epoxy-benzoxazine copolymer network. Water-based epoxy-benzoxazine emulsions were prepared using two benzoxazine surfactants and different epoxy resins. Thin epoxy-benzoxazine films were prepared directly from emulsions to investigate, if benzoxazine surfactant could be properly incorporated into the epoxy structure after drying, film formation and curing process, which is of great importance for possible industrial applications. Thermal properties and hardness of cured films were investigated as well.

\section{Experimental}

\subsection{Materials}

Paraformaldehyde ( $\geq 95.0 \%), 3,3$ '-dimetoxybenzidine (o-dianisidine), sodium hydroxide and anhydrous sodium sulfate $(\geq 99.0 \%)$ were purchased from Sigma Aldrich, Chemie GmbH, Steinheim, Germany. Synthetic epoxy resins of bisphenol A diglycidyl ether type with different molar weights were purchased from Sigma Aldrich Co., St. Louis, MO, USA. The epoxy resins with molar weights 340,377 and $1750 \mathrm{~g} / \mathrm{mol}$, are further referred to as Epoxy 340, Epoxy 377 and Epoxy 1750, respectively. As a bio-renewable resin, epoxidized soybean oil (Drapex 39, Galata Chemicals, Southbury, CT, USA) with $6.5 \%$ epoxy oxygen content and epoxide equivalent weight $246 \mathrm{~g} / \mathrm{eq}$, was used. Phenolic components, bisphenol A $(\geq 98.0 \%)$ and 4tert-butylphenol ( $\geq 98.0 \%)$, along with chloroform $(\geq 99.0 \%)$ and dichloromethane $(\geq 99.0 \%)$ were used as received from Merck KGaA, Darmstadt, Germany. Polyether monoamine (Jeffamine M-1000, molar weight $1000 \mathrm{~g} / \mathrm{mol}$ ) and N-phenyl bisphenol A based 1,3-benzoxazine (Araldite MT $35600 \mathrm{CH}$, BA-a benzoxazine) were received from Huntsman Holland BV, Rozenburg, Holland and Huntsman Advance Materials BVBA, Everberg, Belgium, respectively. Chemical structures of epoxy, benzoxazine and amine materials used are depicted in Figure 1.

\subsection{Synthesis of benzoxazine surfactants}

Benzoxazine surfactants were synthesized from Jeffamine M-1000, phenol component (bisphenol A or 4-tert-butylphenol) and paraformaldehyde. Chloroform was used as a solvent for all syntheses.

\section{Synthesis of 4-tert-butylphenol-based surfactant}

The 4-tert-butylphenol-based benzoxazine surfactant (Figure 2a) was synthesized according to 
<smiles>CCOCCOc1ccc(C(C)(C)c2ccc(OCC3CO3)cc2)cc1</smiles>
Epoxy $340\left(M_{n}=340 \mathrm{~g} / \mathrm{mol}\right)$<smiles>CC(C)(c1ccc2c(c1)CN(c1ccccc1)CO2)c1ccc2c(c1)CN(c1ccccc1)CO2</smiles>

$\mathrm{N}$-phenyl bisphenol A based 1,3-benzoxazine (Araldite MT $35600 \mathrm{CH}$ )<smiles>COc1ccc(C(C)(C)c2ccc(OCC(O)COc3ccc(C(C)(C)c4ccc(OCC5CO5)cc4)cc3)cc2)cc1</smiles>

Epoxy $377\left(M_{n}=377 \mathrm{~g} / \mathrm{mol}\right)$ and Epoxy $1750\left(M_{n}=1750 \mathrm{~g} / \mathrm{mol}\right)$<smiles>CCCCCCCCC(=O)OCC(COC(=O)CCCCCCCCC1OC1CCCCCCCC1OC1CCCCCCC1OC1CC1OC1CCCCCC)OC(=O)CCCCCCCC1OC1CC1OC1CCCCC</smiles>

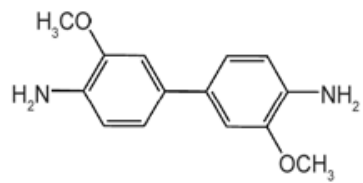

3,3'-Dimetoxybenzidine (o-dianisidine)

Epoxidized soybean oil (Drapex 39)

Figure 1. Chemical structures of epoxy and benzoxazine resins as well as amine curing agent used in this study

Chernykh et al. [22]. Jeffamine M-1000 (50.0 g, $0.05 \mathrm{~mol}$ ) and paraformaldehyde (3.003 g, $0.1 \mathrm{~mol}$ ) were stirred in a round-bottomed flask in $80 \mathrm{~mL}$ of chloroform at room temperature for 30 minutes, and then 4-tert-butylphenol (7.511 g, $0.05 \mathrm{~mol}$ ) was added. The reaction mixture was refluxed for $24 \mathrm{~h}$ in a flask equipped with a condenser. The reaction was followed by thin layer chromatography (TLC). A yellow viscous liquid solution was obtained. The solution was washed three times with $1 \mathrm{M} \mathrm{NaOH}$ aqueous solution and finally several times with distilled water, until neutral $\mathrm{pH}$ value. The organic

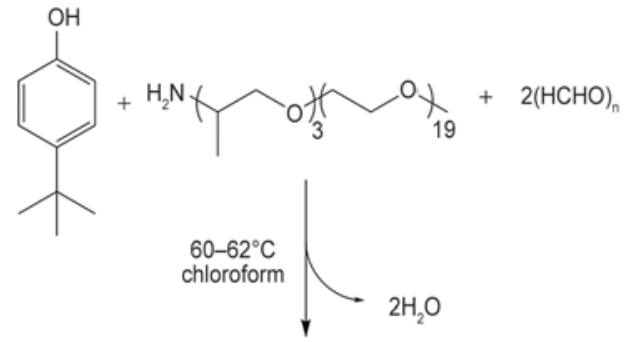

a)

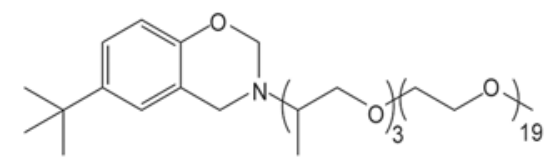

Boxsurf 1 phase was dried with anhydrous $\mathrm{Na}_{2} \mathrm{SO}_{4}$ and the solvent was removed at low pressure. A yellowish solid was obtained (yield $\sim 85 \%$ ). This benzoxazine surfactant is further referred to as Boxsurf 1 .

\section{Synthesis of bisphenol A-based surfactant}

Bisphenol A-based benzoxazine surfactant (Figure $2 b$ ) was prepared by analogy to the procedure described above for the synthesis of 4-tert-butylphenol-based benzoxazine surfactant. Because of the bi-functionality of bisphenol $\mathrm{A}$, the molar ratio of phenol, paraformaldehyde and Jeffamine M-1000

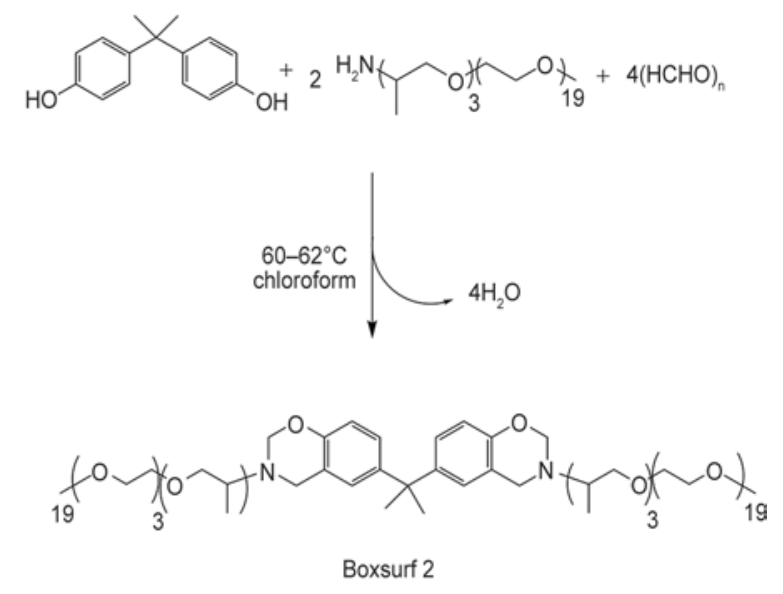

Figure 2. Synthesis of benzoxazine surfactants from Jeffamine M-1000, paraformaldehyde and phenolic compounds (4-tert-butyl phenol for synthesis of Boxsurf 1 (a) and bisphenol A for synthesis of Boxsurf 2 (b)) 
was changed from 1:2:1 to 1:4:2. A yellowish solid was obtained (yield $\sim 90 \%$ ). This benzoxazine surfactant is further referred to as Boxsurf 2.

The formation of both benzoxazine surfactants was confirmed by Fourier transform infrared spectroscopy (FT-IR) using $\mathrm{KBr}$ disks on Perkin Elmer Spectrum 1000 spectrometer (Waltham, USA) and by ${ }^{1} \mathrm{H}$ nuclear magnetic resonance (NMR) analysis on Bruker Avance III $500 \mathrm{MHz}$ NMR spectrometer (Billerica, USA). By FT-IR analysis also polymerization of benzoxazines at three different temperatures $\left(150,180\right.$ and $\left.210^{\circ} \mathrm{C}\right)$ was investigated.

\subsection{Preparation of epoxy emulsions with benzoxazine surfactants}

A chosen amount of benzoxazine surfactant was solubilized in $6.5 \mathrm{~g}$ of water (continuous phase) and heated to $60^{\circ} \mathrm{C}$. The pure epoxy resins (dispersed phase) were heated to $60^{\circ} \mathrm{C}$ as well. Elevated temperature was necessary to ensure lower viscosity of the dispersed phase. The continuous and dispersed phases were mixed together at elevated temperature $\left(60^{\circ} \mathrm{C}\right)$ using a vortex stirrer (Ultra-Turrax IKA T25, Staufen, Germany) at $8400 \mathrm{rpm}$ for $1 \mathrm{~h}$. Weight ratio between water and dry matter (epoxy and benzoxazine) was constant for all experiments, namely 1:1. Emulsions prepared by this procedure were slowly cooled to room temperature. Average particle sizes and distributions of so prepared emulsions were determined using Microtrac Bluewave, FLEX 10.6.2 (Meerbusch, Germany) instrument. $O$-dianisidine $(0.65 \mathrm{~g})$, which was used as a curing agent for the curing process of epoxy-benzoxazine system, was dissolved in a small amount of dichloromethane. The solution of dichloromethane and curing agent was mixed with pre-prepared emulsions at room temperature. This ensures no polymerization or curing process of epoxy resins during emulsification.

\subsection{Preparation of epoxy-polybenzoxazine thin films}

Epoxy-polybenzoxazine thin films were made directly from aqueous emulsions containing the curing agent. Approximately $5 \mathrm{~g}$ of the emulsion was transferred to a glass plate by a four sided applicator frame (Zehntner ZAF 2010, Sissach, Switzerland) and $120 \mu \mathrm{m}$ thick films were made. Three films for emulsion formulation were made. Films were dried

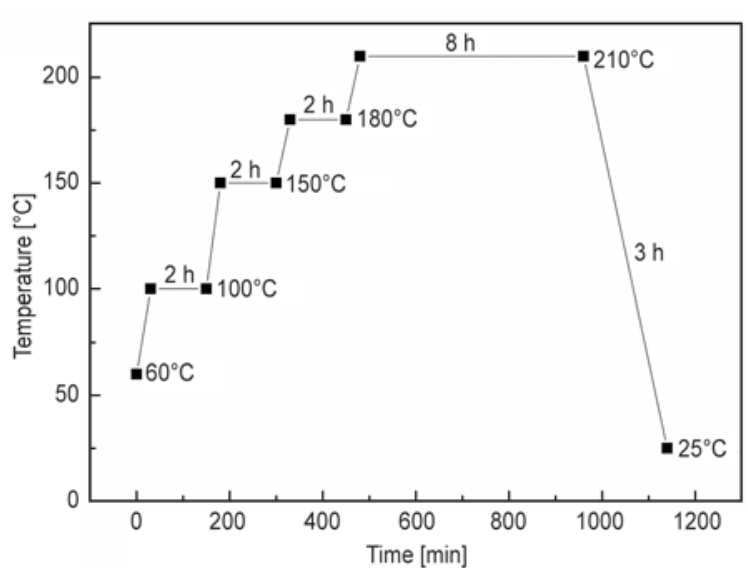

Figure 3. Cure cycle of epoxy-benzoxazine thermosetting copolymers

and cured according to the temperature program shown in Figure 3 in a programmable thermostatic oven (APT. line ${ }^{\mathrm{TM}} \mathrm{FP}$, Binder, Tuttlingen, Germany). The long residence time at $210^{\circ} \mathrm{C}$, recommended also by group of Grishchuk [14, 15, 18], was selected based on FT-IR analysis to achieve complete curing of both epoxy and benzoxazine resins. Transparent brownish epoxy-polybenzoxazine thin films were obtained after curing.

\subsection{Curing and thermal properties of epoxy-polybenzoxazine thin films}

Curing behavior of each resin was studied using differential scanning calorimetry (DSC, DSC 1, Mettler Toledo, Greifensee, Switzerland). Before DSC measurements the water from emulsions was evaporated at $50^{\circ} \mathrm{C}$ and under low pressure. Curing agent was added after drying to prevent curing during drying. Then $5-8 \mathrm{mg}$ of samples were sealed in an aluminum pan with a lid. The purge nitrogen gas flow was maintained to be constant at $30 \mathrm{~mL} / \mathrm{min}$. The samples were heated from -100 to $300^{\circ} \mathrm{C}$ using $10^{\circ} \mathrm{C} / \mathrm{min}$ heating rate. Two heating runs for each sample were performed. From DSC results also $T_{\mathrm{g}}$ of non-cured and cured epoxy-polybenzoxazine films could be determined.

\subsection{Hardness measurement}

\section{Pendulum hardness}

A König pendulum hardness tester (BYK pendulum hardness tester, Wesel, Germany) was used to measure the surface hardness of the cured films. The pendulum hardness is determined by measuring oscillation time of pendulum from 6 to $3^{\circ}$ at room temperature. This test is based on the principle that the 
harder the measured surface, the greater the amplitude time of pendulum oscillation (ASTM D 4366). The glass plate was used as a reference sample.

\section{Pencil hardness}

A Pencil hardness measurement is a relatively simple method to determine the hardness of coating films. The investigated film is placed on a firm horizontal surface and the pencil is held firmly against the film at $45^{\circ}$ angle and pushed away from the operator in a $6.5 \mathrm{~mm}$ stroke. The minimum hardness able to scratch the surface of the cured film was determined by this method with BYK 5800 pencil hardness tester (Wesel, Germany) (ASTM D 3363-74, 2000) [23].

\section{Results and discussion}

Both synthesized benzoxazine surfactants consist of a hydrophobic head group with benzoxazine unit and a hydrophilic polyether tail. The long polyether chain consists of hydrophilic poly(ethylene oxide), PEO and hydrophobic poly(propylene oxide), PPO. Jeffamine M-1000 used in this study contains 19 PEO units and only 3 PPO units. The theoretical values for the hydrophobic-lipophilic balance, HLB, according to Griffin [24] were calculated from the different molar weight of hydrophobic and hydrophilic units of molecule of surfactants. HLB values for both surfactants were 14, which indicate a predominantly hydrophilic character of synthesized surfactants and potential ability for stabilization of $\mathrm{o} / \mathrm{w}$ emulsions [20, 21].

\subsection{Characterization of benzoxazine surfactants}

The chemical structure of benzoxazine surfactants was confirmed by FT-IR and ${ }^{1} \mathrm{H}$ NMR spectroscopy. As representative example the FT-IR spectrum of Boxsurf 2 is shown in Figure 4, where the characteristic signal for oxazine ring, which corresponds to the asymmetric stretching vibration of $\mathrm{C}-\mathrm{O}-\mathrm{C}$ group, can be observed at around $1250 \mathrm{~cm}^{-1}$. The formation of the tri-substituted aromatic ring was confirmed by typical signals at around 1503 and $952 \mathrm{~cm}^{-1}$, while the strongest absorption band at $1105 \mathrm{~cm}^{-1}$ corresponds to $\mathrm{C}-\mathrm{O}-\mathrm{C}$ stretching vibration of polyether chain $[20,21]$.

Curing and polymerization of benzoxazine surfactants was investigated with FT-IR analyses as well. In Figure 4 the FT-IR spectra of Boxsurf 2 after its

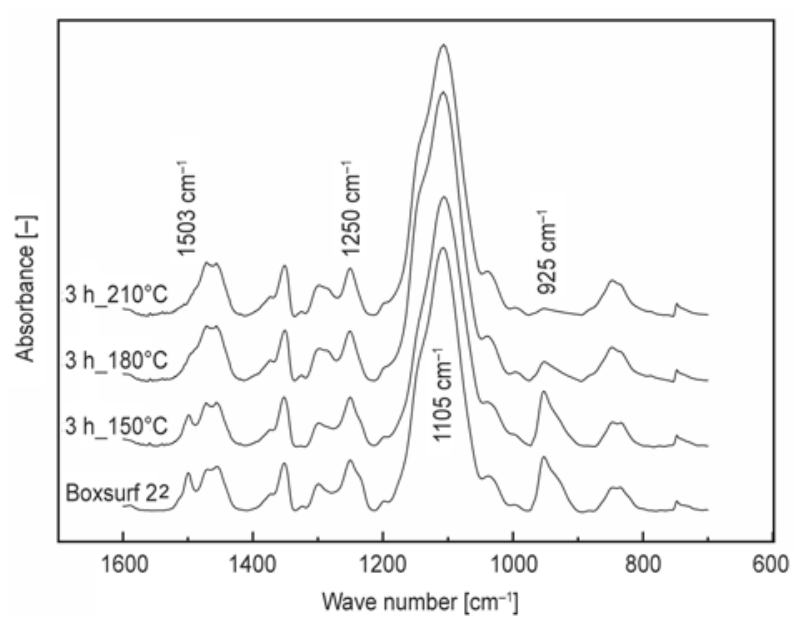

Figure 4. FT-IR spectra of Boxsurf 2 before and after $3 \mathrm{~h}$ of polymerization at 150,180 and $210^{\circ} \mathrm{C}$

exposure to different elevated temperatures for 3 hours are shown. The diminishment or disappearance of signals at 1503 and $952 \mathrm{~cm}^{-1}$ confirmed benzoxazine curing. During curing, the peak at $1503 \mathrm{~cm}^{-1}$ disappears and shifts to around $1450 \mathrm{~cm}^{-1}$ because tri-substituted aromatic ring becomes tetrasubstituted. Due to curing also the peak at $952 \mathrm{~cm}^{-1}$ disappears, as a result of oxazine ring-opening process. Results in Figure 4 clearly indicated that Boxsurf 2 should be cured for at least 3 hours or longer at $210^{\circ} \mathrm{C}$ to achieve a high degree of cure. The ${ }^{1} \mathrm{H}$ NMR spectroscopy (Figure 5) enabled determination of the amount of benzoxazine rings in benzoxazine surfactants. The amount of closed benzoxazine rings in Boxsurf 2 was calculated from the ratio between signals at $4.9 \mathrm{ppm}$ (corresponding to oxazine $-\mathrm{CH}_{2}$ group in $-\mathrm{O}-\mathrm{CH}_{2}-\mathrm{N}$ - group) and $1.6 \mathrm{ppm}$ (corresponding to methyl groups of bisphenol A). It was found that $75 \%$ of Boxsurf 2 was bifunctional (had two benzoxazine units) and the rest was mono-functional. On the other hand, the amount of closed benzoxazine rings in Boxsurf 1, which was calculated from the ratio between signals at 4.9 and $1.3 \mathrm{ppm}$ (corresponding to methyl group of $t$ butyl group), was $90 \%$. Accordingly, the spectra of Boxsurf 1 and Boxsurf 2 also showed that some unreacted phenol (signals at $7.2 \mathrm{ppm}$ ) was still present. Other characteristic signals in ${ }^{1} \mathrm{H}$ NMR spectra were attributed to oxazine $-\mathrm{CH}_{2}$ group in $\mathrm{Ph}-\mathrm{CH}_{2}-\mathrm{N}-$ group (at $4.0 \mathrm{ppm}$ ), to methylene groups of the polyether chain (from 3.3 to $3.7 \mathrm{ppm}$ ) and to aromatic rings (from 6.6 to $7.1 \mathrm{ppm}$ ) [20,21]. The purity of Boxsurf 1 and Boxsurf 2, calculated from NMR data, was 91 and $72 \%$, respectively. 


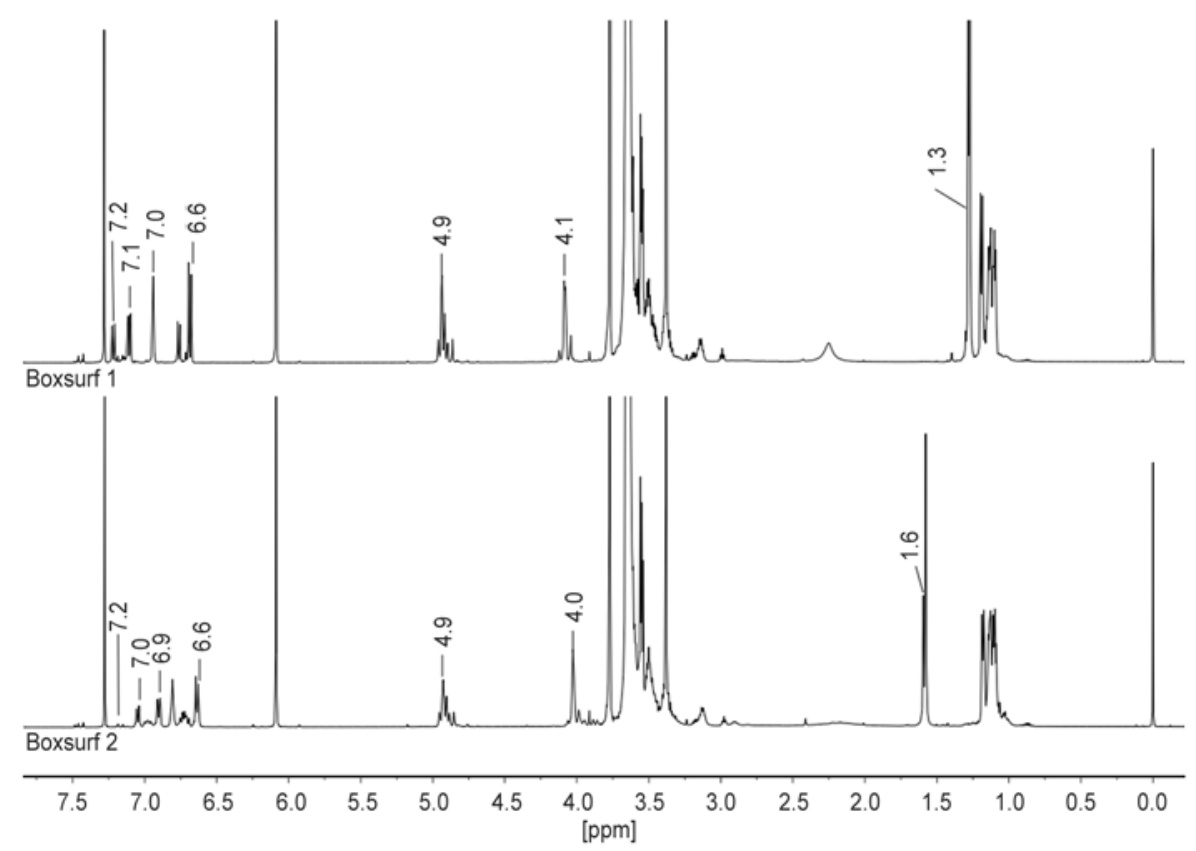

Figure 5. ${ }^{1} \mathrm{H}$ NMR spectra of Boxsurf 1 and Boxsurf 2 in $\mathrm{CDCl}_{3}$

\subsection{Formation and stability of epoxy emulsions}

The aim of the next part of the research was to check if stable epoxy water-based emulsions could be obtained by using synthesized benzoxazines as surfactants. The emulsions were made following the procedure described in the experimental section. Different epoxy resins were chosen as dispersed phase. Effects of surfactant amount and molar weight of epoxy resins on the emulsion average particle size and distribution and emulsion stability were studied. Detailed compositions of investigated emulsions are collected in Table 1. High amount of surfactants were chosen, so epoxy-benzoxazine copolymerization process after emulsification, can be studied.

The viscosity of dispersed phase is one of the crucial criteria for the preparation of stable o/w emulsions, because a too big difference in viscosity between dispersed and continuous phases may leads to unstable emulsion system $[20,21,25]$. In the worst case emulsion cannot be obtained at all. Due to high viscosities of epoxy resins at room temperature and to prevent epoxy resin cooling during emulsification step, dispersed and continuous phase were first heated to $60^{\circ} \mathrm{C}$. In experiments with Epoxy 1750 the temperature was still too low to ensure a sufficient reduction of viscosity and a solvent (dichloromethane) was added to the dispersed phase to further reduce the viscosity of the system. However it was still impossible to obtain a stable emulsion with Epoxy 1750.
After emulsification, the emulsions were stored in covered test tubes at room temperature to determine their stability with time. It was observed that after 3-4 days almost all systems showed a tendency to settle. The extent of settling increased with decreasing concentration of Boxsurf 1 or Boxsurf 2. Emulsions with Boxsurf 1 showed slightly better stability compared to emulsions with Boxsurf 2 , although the HLB value of surfactants was very similar. The hydrophobic part of the Boxsurf 2 molecule is entrapped between two hydrophilic tails (Figure 2), which may hinder hydrophobic interactions between emulsifier and epoxy resin in emulsions. On the other hand, the emulsion stability decreased with increasing molar weight of the epoxy resin applied mainly due to the increased particle size, which was a consequence of higher resin viscosity. However, when the covered test tubes containing samples, which had settled, were just lightly shaken by hand, emulsions easily became perfectly homogenous again. This is of great importance especially for application purposes. The only system, which was stable even after a few weeks of storage and did not show any signs of settling, was the system with Drapex 39. This is due to low density of epoxidized soybean oil $\left(0.99 \mathrm{~g} / \mathrm{mL}\right.$ at $\left.25^{\circ} \mathrm{C}\right)$. The density of synthetic epoxy resins was $1.16 \mathrm{~g} / \mathrm{mL}$ at $25^{\circ} \mathrm{C}$.

Table 1 summarizes results of number average particle size $\left(d_{\text {num }}\right)$ and particle size distribution measurements for emulsions with different epoxy resins and concentrations of benzoxazine surfactants. It 
Table 1. Number average particle diameters $\left(d_{\text {num }}\right)$ and polydispersity indexes $\left(d_{\mathrm{vol}} / d_{\text {num }}\right)$ for emulsions measured immediately after emulsification and after one week of storage. Mass of water was the same for all emulsions (6.5 g).

\begin{tabular}{|c|c|c|c|c|c|c|c|}
\hline \multirow{4}{*}{ Emulsion } & \multirow{4}{*}{$\begin{array}{c}\begin{array}{c}\text { Epoxy resin } \\
\text { amount }\end{array} \\
{[\mathrm{g}]}\end{array}$} & \multirow{2}{*}{\multicolumn{2}{|c|}{ Surfactant amount }} & \multicolumn{4}{|c|}{ Average particle size and distribution } \\
\hline & & & & \multicolumn{2}{|c|}{ Immediately } & \multicolumn{2}{|c|}{${ }^{*}$ After 1 week } \\
\hline & & & & \multirow{2}{*}{$\begin{array}{l}d_{\text {num }} \\
{[\mu \mathrm{m}]}\end{array}$} & \multirow{2}{*}{$\frac{d_{\text {vol }} / d_{\text {num }}}{[-]}$} & \multirow{2}{*}{$\begin{array}{l}d_{\text {num }} \\
{[\mu \mathrm{m}]} \\
\end{array}$} & \multirow{2}{*}{$\frac{d_{\mathbf{v o l}} / d_{\text {num }}}{[-]}$} \\
\hline & & [g] & {$[g / L]$} & & & & \\
\hline \multicolumn{8}{|c|}{ Epoxy 340/Boxsurf 2} \\
\hline E.1 & 5.69 & 0.81 & 125 & 0.80 & 10.7 & 0.91 & 11.3 \\
\hline E. 2 & 5.57 & 0.93 & 143 & 0.87 & 10.0 & 0.84 & 11.1 \\
\hline E. 3 & 5.41 & 1.09 & 168 & 0.87 & 9.4 & 0.97 & 9.8 \\
\hline E.4 & 5.20 & 1.30 & 200 & 0.89 & 5.9 & 0.96 & 8.1 \\
\hline E.5 & 4.88 & 1.62 & 249 & 0.97 & 4.2 & 1.30 & 5.3 \\
\hline E.6 & 4.34 & 2.16 & 332 & 1.09 & 3.2 & 1.55 & 3.7 \\
\hline \multicolumn{8}{|c|}{ Epoxy 340/Boxsurf 1} \\
\hline E.7 & 5.41 & 1.09 & 168 & 0.85 & 7.5 & 0.91 & 8.7 \\
\hline E.8 & 5.20 & 1.30 & 200 & 0.85 & 6.9 & 1.20 & 5.0 \\
\hline E.9 & 4.88 & 1.62 & 249 & 0.93 & 3.6 & 1.41 & 3.1 \\
\hline \multicolumn{8}{|c|}{ Epoxy 377/Boxsurf 2} \\
\hline E.10 & 5.41 & 1.09 & 168 & 0.72 & 10.9 & 0.86 & 11.1 \\
\hline E.11 & 5.20 & 1.30 & 200 & 0.78 & 7.1 & 0.87 & 8.0 \\
\hline E.12 & 4.88 & 1.62 & 249 & 0.91 & 4.1 & 1.00 & 4.4 \\
\hline \multicolumn{8}{|c|}{ Epoxy 1750/Boxsurf 2} \\
\hline E.13 & 5.41 & 1.09 & 168 & \multicolumn{4}{|c|}{ not stable } \\
\hline E.14 & 5.20 & 1.30 & 200 & \multicolumn{4}{|c|}{ not stable } \\
\hline E.15 & 4.88 & 1.62 & 249 & \multicolumn{4}{|c|}{ not stable } \\
\hline \multicolumn{8}{|c|}{ Drapex 39/Boxsurf 2} \\
\hline E.16 & 5.41 & 1.09 & 168 & 0.82 & 3.0 & 0.77 & 4.4 \\
\hline E.17 & 5.20 & 1.30 & 200 & 0.64 & 3.4 & 0.64 & 3.8 \\
\hline E.18 & 4.88 & 1.62 & 249 & 0.83 & 2.7 & 0.77 & 3.7 \\
\hline
\end{tabular}

*Emulsions were shaken only by hand prior to measurements
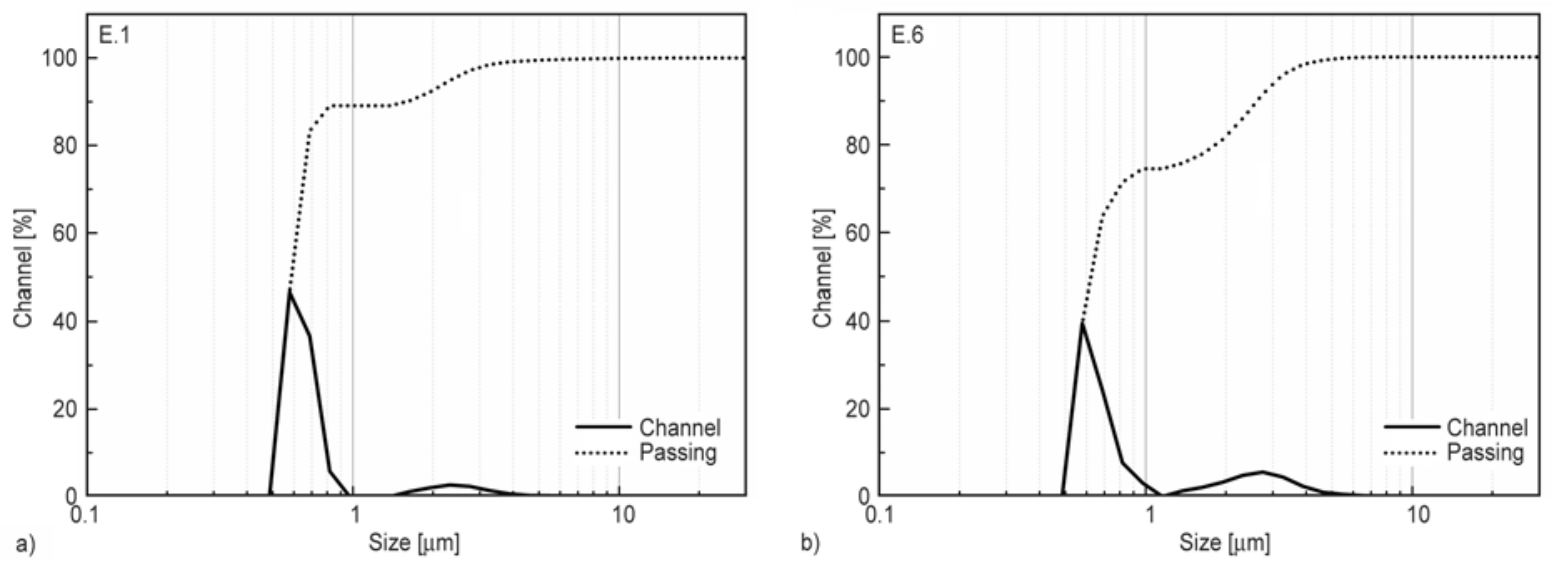

Figure 6. Number particle size distribution for emulsion E.1 (a) (12.5\% Boxsurf 2 and 87.5\% Epoxy 340) and emulsion E.6 (b) (33.3\% Boxsurf 2 and 66.7\% Epoxy 340) determined immediately after emulsification

may be seen in Table 1 that emulsions with the lowest average particle size were obtained for the emulsion containing epoxidized soybean oil, i.e. for the system with the lowest viscosity and density of the dispersed phase.

However, bimodal particle size distribution curves for emulsions were observed (Figure 6). The more intense peak, representing the diameter of a major number part of particles, appeared between 0.5 and
$1 \mu \mathrm{m}$. The second peak was broader and appeared above $1 \mu \mathrm{m}$ (with peak maximum between 2 and $3 \mu \mathrm{m})$. Interestingly the magnitude of the second peak increased with increasing surfactants amounts. Since surfactant should be in excess, the first peak most likely represented the size of epoxy particles, emulsified by the surfactant, while the second peak represented the size of clusters of unused surfactant. This was confirmed by particle size measure- 
ment of pure surfactant emulsions, where a single peak with maximum at around $2.5 \mu \mathrm{m}$ was observed. Therefore it may be concluded that molecules of the surfactant were in excess and effectively covered the surface of epoxy particles with diameter between 0.5 and $1 \mu \mathrm{m}$.

Pure surfactant particles are large due to the hydrophilic nature of polyether tails, which swell in water. The result of this phenomenon is the increasing number average particle size of emulsions with increasing benzoxazine concentration, which is not usual. For example, the number average particle size for emulsion Epoxy 340/Boxsurf 2, was increasing from 0.80 to $1.09 \mu \mathrm{m}$ when concentration of benzoxazine surfactant increased from 125 to $332 \mathrm{~g} / \mathrm{L}$. Ratio between volume $\left(d_{\mathrm{vol}}\right)$ and number $\left(d_{\text {num }}\right)$ average particle diameters $\left(d_{\mathrm{vol}} / d_{\text {num }}\right)$, as a measure for the polydispersity, decreased with increasing surfactant concentration for all emulsions, because dnum increased and dvol decreased with surfactant concentration. The dnum increase and simultaneous dvol decrease for such systems were observed elsewhere [20, 21, 25-27].

Since emulsions showed a tendency to settle after a few days, particle diameters were measured again after one week. Before measurements the test tubes containing emulsions were shaken (only by hand) to obtain homogeneous systems. The measured results are listed in Table 1 and are very similar to the results obtained immediately after emulsification. This suggested that emulsions were stable (they only settle, but not coagulate) and may be used for practical applications. The settling, which depended on the amount of surfactant used, was due to difference in density between dispersed and continuous phase. Over time the two peaks in distribution curves separated even more, indicating some surfactant redistribution between particles and confirming that two different kinds of particles did not coagulate. As a consequence also $d_{\mathrm{vol}} / d_{\text {num }}$ values increased just slightly with time.

\subsection{Curing behavior of epoxy-benzoxazine films}

Thermal properties of both surfactants were investigated by DSC analysis using two heating runs. Figures 7 and 8 show thermograms in higher and lower temperature region of interest, respectively. In DSC thermogram, obtained at heating rate $10^{\circ} \mathrm{C} / \mathrm{min}$, Boxsurf 1 showed an exothermic peak, which corresponded to curing, with onset $\left(T_{\mathrm{i}}\right)$ and maximum
$\left(T_{\mathrm{p}}\right)$ at 230 and $262^{\circ} \mathrm{C}$, respectively. Boxsurf 2 had $T_{\mathrm{i}}$ and $T_{\mathrm{p}}$ at 205 and $250^{\circ} \mathrm{C}$, respectively. Boxsurf 1 released less heat $(27.5 \mathrm{~J} / \mathrm{g})$ than Boxsurf $2(32.2 \mathrm{~J} / \mathrm{g})$ during its curing process. Results in Figure 7 indicate that higher benzoxazine functionality of Boxsurf 2 shifted the onset temperature of the curing process to a lower temperature. However, the curing temperature intervals for both surfactants were very broad; the peaks in Figure 7 extended up to almost $300^{\circ} \mathrm{C}$. We believe this was because of the steric hindrance of the curing process, which was induced by long polyether chains.

To estimate the effect of polyether chains on curing, N-phenyl bisphenol-A based 1,3-benzoxazine (BAa benzoxazine), was scanned by the same DSC method (Figure 7). Results showed that considerably more heat were released during BA-a benzoxazine curing $(300 \mathrm{~J} / \mathrm{g})$ and that the exothermic peak was not as broad as for benzoxazine surfactants. Similar results were obtained also by Ning and Ishida $[28,29]$. The main reason for differences in reaction enthalpy is, without doubt, the chemical structure of benzoxazine surfactants, which contain long hydrophilic tails and have therefore less reactive oxazine groups per gram of material. The steric hindrance induced by long polyether tails prolonged the curing process to higher temperatures.

The catalytic effect of amine moieties on curing processes of benzoxazines was demonstrated and published by several authors $[2,10,13-15]$. $O$-dianisidine $(10 \mathrm{wt} \%)$, with diamine structure, was used as

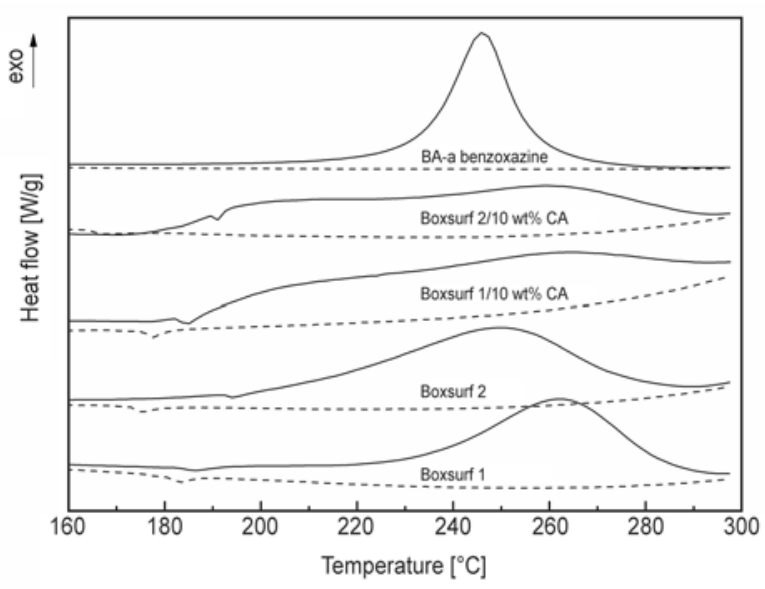

Figure 7. DSC thermograms of Boxsurf 1 and Boxsurf 2 with and without $10 \mathrm{wt} \%$ of curing agent and DSC thermograms of BA-a benzoxazine in the curing temperature range. Full lines represent first heating runs (material before cure) and dashed lines represent second heating runs (cured material). 
curing agent to reduce the temperature of curing. Added curing agent had a positive effect on the curing process of both surfactants (Figure 7), since the onset temperature of curing was reduced. However, as a consequence of lowered curing onset temperature, even broader exothermic peaks were observed. This indicates that during the curing process different reactions take place $[8,14,15,17,19]$. Figure 7 also shows that benzoxazine surfactants were completely cured already after first DSC runs, since no exothermic peak was observed in DSC thermograms of second runs. To estimate the effect of added curing agent on degree of cure, isothermal curing of benzoxazine surfactants, with and without curing agent, was carried out at $180^{\circ} \mathrm{C}$ for 30 minutes. Then dynamic DSC thermograms were scanned and the degree of cure was calculated according to Equation (1):

Degree of cure $[\%]=\left(1-\frac{\Delta H_{\mathrm{r}}}{\Delta H_{0}}\right) \cdot 100$

where $\Delta H_{\mathrm{r}}$ is the heat of reaction of the partially cured specimen and $\Delta H_{0}$ is the heat of reaction of the uncured resin. Degree of cure after 30 minutes at $180^{\circ} \mathrm{C}$ increased with the addition of the curing agent (10 wt $\%$ ) from 17.4 to $68.0 \%$ and from 39.3 to $72.3 \%$ for Boxsurf 1 and Boxsurf 2, respectively. Positive effect of curing agent addition was thus clearly seen in both cases, although broader curing peaks were observed in DSC thermograms (Figure 7) when $o$-dianisindine was added.

In DSC thermograms of Boxsurf 1 and Boxsurf 2 in the lower temperature region (Figure 8 ) an endothermic peaks due to a pronounced melting transition could be observed. The minimums of melting peaks of Boxsurf 1 and Boxsurf 2 were observed at 29 and $30^{\circ} \mathrm{C}$, respectively. These melting transitions were observable also after curing, because polyether chains, which melted, were not involved in curing reactions. Added curing agent had no impact on melting.

Curing behavior of epoxy-benzoxazine films was investigated next. The aim of this investigation was to confirm if benzoxazine molecules are well incorporated in the epoxy structure upon emulsification, film formation and curing and to investigate how different molar weights of epoxy resin and different benzoxazine contents influence on film curing process. For curing $10 \mathrm{wt} \%$ of $o$-dianisidine as curing agent was used.

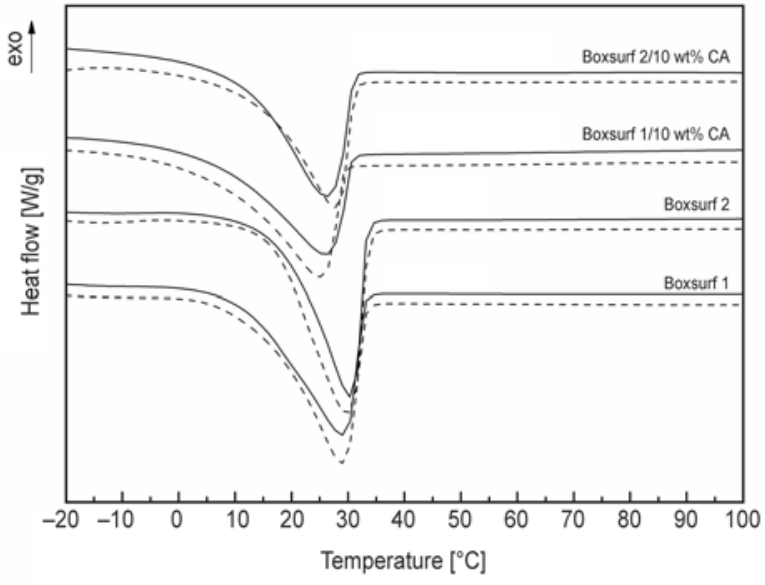

Figure 8. DSC thermograms of Boxsurf 1 and Boxsurf 2 with and without $10 \mathrm{wt} \%$ of curing agent in the polyether chains melting temperature range. Full lines represent first heating runs (material before cure) and dashed lines represent second heating runs (cured material).

Curing parameters of neat epoxy and neat benzoxazine resins, as well as curing parameters of their mixtures, are listed in Table 2. In accordance with the literature [14, 15, 30-32], epoxy resins, if a proper curing agent is used, usually polymerize at lower temperatures than benzoxazine resins, which is well observed by comparing Figures 7 and 9 . The only exception was found for systems with Drapex 39, where no curing process was detected under these conditions. To achieve fully cross-linked structure of Drapex 39, the concentration of added curing agent should be higher (stoichiometric ratio) and the time of curing should be longer. We must be aware of the fact that epoxidized soybean oil is a large triglyceride molecule (Figure 1) with large steric barriers that

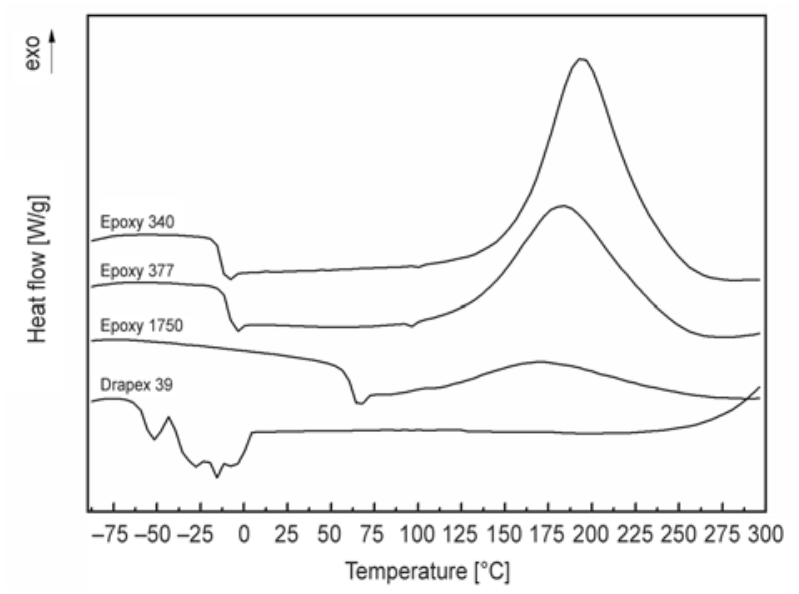

Figure 9. DSC thermograms of Epoxy 340, Epoxy 377, Epoxy 1750 and Drapex 39 with $10 \mathrm{wt} \%$ of $o$ dianisidine in the temperature range from -100 to $300^{\circ} \mathrm{C}$ with heating rate $10^{\circ} \mathrm{C} / \mathrm{min}$ 
Table 2. Curing parameters of epoxy-benzoxazine mixture with addition $10 \mathrm{wt} \%$ of curing agent

\begin{tabular}{|c|c|c|c|c|c|c|c|}
\hline \multirow[t]{2}{*}{ Film } & $\begin{array}{c}\text { Surfactant } \\
\text { content }\end{array}$ & $\begin{array}{c}\text { Epoxy } \\
\text { content }\end{array}$ & $\begin{array}{c}\text { Onset temperature } \\
\left(T_{\mathrm{i}}\right)\end{array}$ & $\begin{array}{c}\text { Peak temperature } \\
\left(T_{\mathrm{P}}\right)\end{array}$ & $\begin{array}{c}\text { Released heat } \\
(\Delta H)\end{array}$ & $\begin{array}{c}T_{\mathrm{g}} \text { of uncured } \\
\text { resin }\end{array}$ & $\begin{array}{c}T_{\mathrm{g}} \text { of cured } \\
\text { resin }\end{array}$ \\
\hline & {$[\%]$} & {$[\%]$} & {$\left[{ }^{\circ} \mathbf{C}\right]$} & {$\left[{ }^{\circ} \mathbf{C}\right]$} & {$[\mathrm{J} / \mathrm{g}]$} & {$\left[{ }^{\circ} \mathbf{C}\right]$} & {$\left[{ }^{\circ} \mathbf{C}\right]$} \\
\hline \multicolumn{8}{|c|}{ Epoxy 340/Boxsurf 2} \\
\hline E.1 & 12.5 & 87.5 & 144 & 193 & 133 & -20 & 65 \\
\hline E.2 & 14.3 & 85.7 & 149 & 193 & 126 & -22 & 63 \\
\hline E. 3 & 16.7 & 83.3 & 151 & 194 & 123 & -22 & 58 \\
\hline E.4 & 20.0 & 80.0 & 151 & 194 & 120 & -25 & 48 \\
\hline E.5 & 25.0 & 75.0 & 154 & 195 & 115 & -27 & 39 \\
\hline E.6 & 33.3 & 66.7 & 154 & 196 & 108 & -32 & 27 \\
\hline \multicolumn{8}{|c|}{ Epoxy 340/Boxsurf 1} \\
\hline E.7 & 16.7 & 83.3 & 154 & 195 & 164 & -23 & 56 \\
\hline E. 8 & 20.0 & 80.0 & 154 & 195 & 154 & -25 & 48 \\
\hline E.9 & 25.0 & 75.0 & 157 & 198 & 128 & -27 & 39 \\
\hline \multicolumn{8}{|c|}{ Epoxy 377/Boxsurf 2} \\
\hline E.10 & 16.7 & 83.3 & 132 & 183 & 128 & -16 & 57 \\
\hline E.11 & 20.0 & 80.0 & 130 & 185 & 101 & -21 & 49 \\
\hline E.12 & 25.0 & 75.0 & 132 & 187 & 97 & -22 & 40 \\
\hline \multicolumn{8}{|c|}{ Epoxy 1750/Boxsurf 2} \\
\hline E.13 & 16.7 & 83.3 & 110 & 170 & 79 & - & 61 \\
\hline E.14 & 20.0 & 80.0 & 111 & 174 & 75 & - & 53 \\
\hline E.15 & 25.0 & 75.0 & 113 & 178 & 70 & - & 42 \\
\hline \multicolumn{8}{|c|}{ Drapex 39/Boxsurf 2} \\
\hline E.16 & 16.7 & 83.3 & - & - & - & -62 & -51 \\
\hline E.17 & 20.0 & 80.0 & 232 & 275 & 15 & -60 & 0 \\
\hline E.18 & 25.0 & 75.0 & 247 & 277 & 9 & -62 & -4 \\
\hline \multicolumn{8}{|c|}{ Pure compounds } \\
\hline Epoxy 340 & 0.0 & 100.0 & 154 & 194 & 202 & -14 & 66 \\
\hline Epoxy 377 & 0.0 & 100.0 & 96 & 183 & 146 & -9 & 83 \\
\hline Epoxy 1750 & 0.0 & 100.0 & 70 & 172 & 53 & 60 & 107 \\
\hline Drapex 39 & 0.0 & 100.0 & - & - & - & $<-30^{*}$ & $<-30^{*}$ \\
\hline Boxsurf 1 & 100.0 & 0.0 & 194 & 213 & 26 & -57 & -35 \\
\hline Boxsurf 2 & 100.0 & 0.0 & 187 & 212 & 31 & -55 & -33 \\
\hline
\end{tabular}

hinder chemical reactions. In addition, the concentration of epoxy groups per weight of the Drapex 39 molecules is significantly lower compared to synthetic epoxy resins [30].

The heat released during curing reactions (reaction enthalpy, $\Delta H$ ) was determined from the area under the exothermic peak in DSC thermograms. Curing of epoxy resins is a more exothermic process than curing of benzoxazine surfactants. Therefore the value of $\Delta H$ decreased with increasing amount of benzoxazine in the mixture (Figure 10). $\Delta H$ value, on the other hand, increased with increasing concentration of epoxy groups in epoxy resin, which is confirmed by Figure 9 and results listed in Table 2, where it can be seen that Epoxy 340, which has the lowest molar weight, releases more heat during curing compared to other epoxy resins.

Some epoxy-benzoxazine combinations have two exothermic peaks in their thermograms (Figure 10),

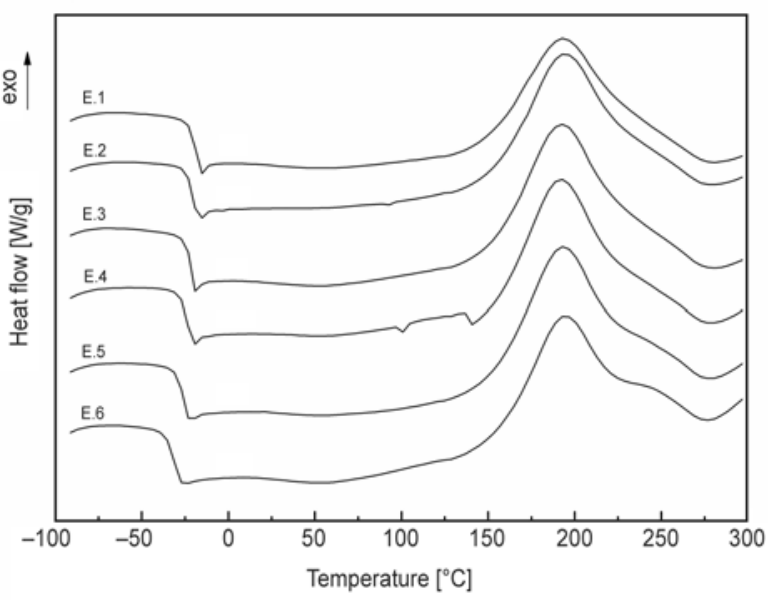

Figure 10. DSC thermograms for uncured system Epoxy 340 /Boxsurf 2 in the range from -100 to $300^{\circ} \mathrm{C}$ with heating rate $10^{\circ} \mathrm{C} / \mathrm{min}$

which became more distinguishable with increasing benzoxazine content, because curing of an epoxybenzoxazine system is a multiple step process including more than one reaction $[8,14,15,17,19]$. 


\subsection{Thermal properties of uncured and cured films}

Thin films were prepared directly from aqueous emulsions. Films could be made even for system Epoxy 1750/Boxsurf 2, although stable emulsions were not obtained. Glass transitions of uncured samples were well defined for all epoxy resins, both surfactants and their blends (films made form emulsions), except for neat Drapex 39, which had a multistep transition; most likely the glass transition (between -60 and $-40^{\circ} \mathrm{C}$ ) was followed by cold crystallization and melting (Figure 9). With increasing molar weight, $T_{\mathrm{g}}$ values of epoxy resins shifted toward higher temperature. The $T_{\mathrm{g}}$ values of uncured resins increased from -14 to $60^{\circ} \mathrm{C}$ when molar weight increased from 340 to $1750 \mathrm{~g} / \mathrm{mol}$, respectively. Uncured benzoxazine surfactants showed their glass transition at lower temperature than epoxy resins; $T_{\mathrm{g}}$ values of -57 and $-55^{\circ} \mathrm{C}$ for Boxsurf 1 and Boxsurf 2 were determined, respectively. For uncured epoxy-benzoxazine films only one $T_{\mathrm{g}}$ was observed, which indicated that homogeneous blends of epoxy and benzoxazine at molecular level were obtained. The incorporation of benzoxazine in epoxy resins resulted in a decreased $T_{\mathrm{g}}$ value (Table 2) as expected. It has to be mentioned, that $T_{\mathrm{g}}$ for uncured Epoxy 1750/Boxsurf 2 film was not obtained because its $T_{\mathrm{g}}$ appears at higher temperature than onset curing $\left(T_{\mathrm{i}}\right)$. In such cases process of vitrification occurs. Due to vitrification signals looking as small endothermic peaks on DSC curves are often observed (Figures 9 and 10).

By comparing Figures 8 and 10 one may observe that combining benzoxazine surfactants with epoxy resins resulted in a complete disappearance of the benzoxazine melting peak (by DSC analysis of Jeffamine M-1000 it was confirmed, that this is the melting peak of polyether chain crystals). This observation supports the observation of a single $T_{\mathrm{g}}$, indicates that benzoxazines were dissolved in epoxy resins to a certain level, and confirms that intermolecular interactions between epoxy and benzoxazine, which prevent crystallization of polyether chains, were formed. It may be assumed that $\mathrm{H}$-bonds present in the epoxy-benzoxazine blend prevented orientation and arrangement of polyether chains into crystal structure. Intermolecular bonds in the epoxy-benzoxazine system have been demonstrated and studied by several authors $[4,15,33,34]$.
Therefore, from results obtained by DSC measurements it may be concluded that benzoxazine surfactant should be homogeneously incorporated in epoxy matrix and that secondary interactions between epoxy and benzoxazine compounds were established.

As expected, the glass transition temperatures of films increased significantly (Table 2, Figure 11) after curing process. Cured films with higher benzoxazine amounts had lower $T_{\mathrm{g}}$ values. For example, the $T_{\mathrm{g}}$ value for system Epoxy 340/Boxsurf 2, decreased from 65 to $27^{\circ} \mathrm{C}$, when the amount of benzoxazine increased from 12.5 to $33.3 \%$. Differences in $T_{\mathrm{g}}$ values of neat epoxy resins and neat benzoxazines are the main reason for such behavior, since cross-linking density of benzoxazine surfactants is probably much lower than that of epoxy resins. The highest $T_{\mathrm{g}}$ values were observed for cured systems containing epoxy resin of the highest molar weight (Epoxy 1750). The increase of cured system $T_{\mathrm{g}}$ value with molar mass of the uncured resin can be explained by non-stoichiometric amount of amine curing agent. In case of stoichiometric epoxy resins/ curing agent ratios, lower cross-linking densities of cured epoxy resins with higher molar weight are expected because of the increase in the chain length between crosslinks. The lowest $T_{\mathrm{g}}$ values were observed for systems with Drapex 39, since these films were not properly cured. As explained before, the large steric hindrance and lower concentration of epoxy groups in Drapex 39 are the main reasons for such behavior.

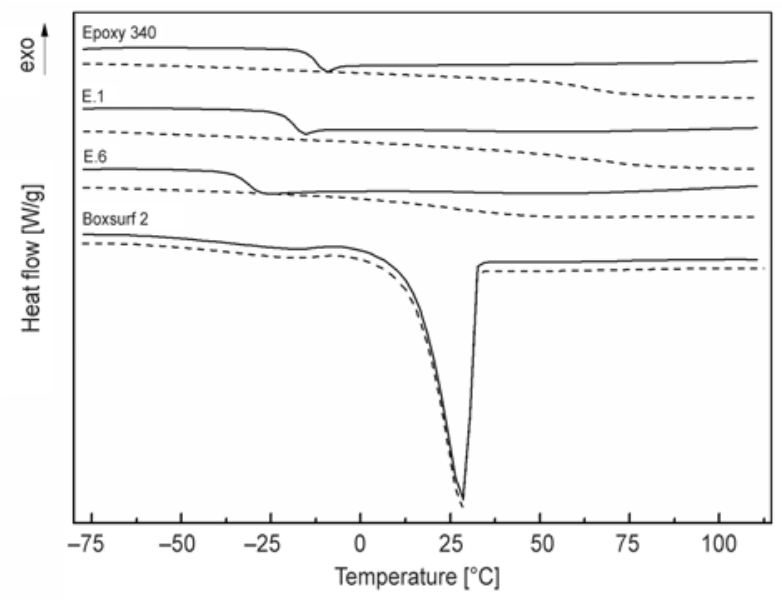

Figure 11. DSC thermograms of Epoxy 340, Boxsurf 2 and their mixtures E.1 (87.5\% Epoxy 340 and $12.5 \%$ Boxsurf 2) and E.6 (66.7\% Epoxy 340 and $33.3 \%$ Boxsurf 2). Full lines represent uncured films and dashed lines represent cured films. 


\subsection{Hardness of cured films}

There are several methods used for measuring the surface hardness of a coating, which give complementary results. The pendulum hardness test (König) and the pencil hardness test were used in the present study.

Pendulum hardness of the cured materials was measured for $120 \mu \mathrm{m}$ thick films (Figure 12a). The measured values for neat epoxy resins were much higher than those for neat benzoxazines. Therefore, pendulum hardness of cured epoxy-benzoxazine films decreased with increasing amount of benzoxazine and also with decreasing molar weight of epoxy resins, as predicted by $T_{\mathrm{g}}$ results. The results showed that cured epoxy-benzoxazine films with small amounts of benzoxazine surfactant had lower pendulum hardness but still comparable to that of the control glass plate, whose hardness was 250 s. Figure 12a also shows that slightly higher film hardness with Boxsurf 2 than Boxsurf 1 was obtained. Boxsurf 2 is a bi-functional molecule with two reactive sites, which probably contribute to higher crosslinking density of cured copolymer network and, consequently, the hardness of films was improved.

The results obtained by pencil hardness tests are shown in Figure 12b. The results were in good agreement with those obtained by pendulum hardness measurements: Pencil hardness of cured films increased with increasing amount and molar weight of epoxy resins. However, a maximum value of pencil hardness was observed for films containing around $80-90 \%$ of epoxy resins and $10-20 \%$ of benzoxazines, which indicated that a lower amount of benzoxazine surfactant even improved surface properties of cured films. The differences between detected tendencies of dependency of pendulum and pencil hardness from benzoxazine content might be sought in principles of hardness determination techniques; the pencil hardness reflects combination of modulus, tensile strength and adhesion properties, while the pendulum hardness depends mainly on the loss factor of investigated coating. Pencil hardness of films for Drapex 39/Boxsurf 2 film could not be determined, because its hardness was lower than that of the softest pencil, 9B.

To conclude, the results of hardness measurements were in excellent agreement with determined $T_{\mathrm{g}}$ values. This means that thermal properties and hardness of cured films improved with the increasing amount of epoxy resins, increasing functionality of benzoxazine surfactant and with increasing molar weight of epoxy resins.

\section{Conclusions}

Mono- and bi-functional benzoxazine nonionic surfactants were successfully synthesized and used as surfactants for water-based epoxy emulsions. All emulsions, except emulsions made with epoxidized soybean oil, settled after few days, but a homogeneous system was easily obtained again, only by light emulsion shaking in a covered test tube. Emulsions contained emulsified epoxy particles and larger clusters of benzoxazine surfactant, indicating that surfactant was in excess and that the molecules of the surfactant effectively covered the surface of epoxy particles. Slightly more stable emulsions with smaller particles were obtained with mono functional benzoxazine surfactant.

Different epoxy resins were used to investigate the impact of molar weight of epoxy resin on the formation and stability of emulsions. By decreasing the molar weight of synthetic epoxy resin the emulsion
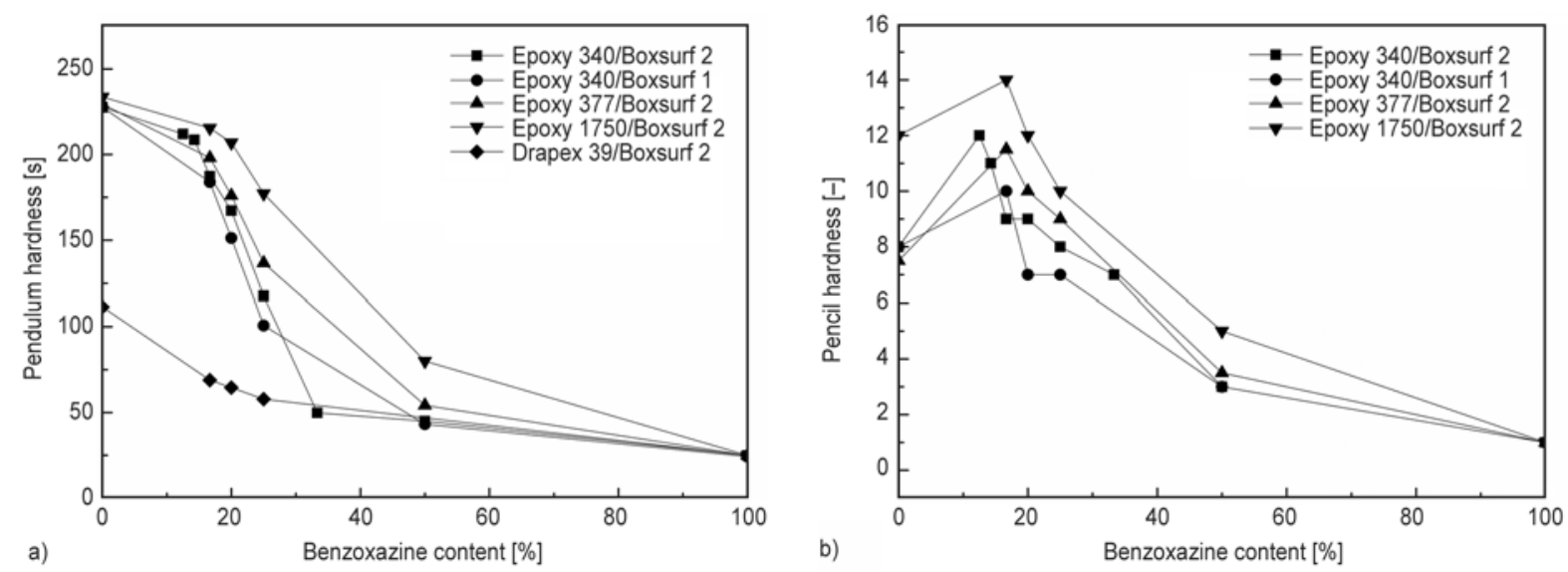

Figure 12. Pendulum hardness (a) and pencil hardness (b) of cured films as a function of benzoxazine content 
stability was improved. It was found that emulsion with epoxidized soybean oil was the most stable and had the smallest average particle size, due to relatively low resin density and viscosity.

Thin films were successfully made directly from emulsions. They were dried and cured in a thermostatic oven at $210^{\circ} \mathrm{C}$. Only one glass transition temperature was observed for films before and after curing, although neat benzoxazine and epoxy had considerably different glass transition temperatures. After curing, the benzoxazine melting point disappeared as well, meaning that epoxy-benzoxazine films were homogeneous at molecular level. $T_{\mathrm{g}}$ values of cured films were higher than those of uncured films. However, results indicate that $T_{\mathrm{g}}$ value of films, before and after curing, and consequently film hardness, decreased with increasing benzoxazine content, which was due to low $T_{\mathrm{g}}$ values of benzoxazine surfactants, containing polyether chains in the structure. $T_{\mathrm{g}}$ values were strongly affected by molar weight of epoxy resin as well.

On the basis of the obtained results, we can conclude that already small amounts $(<12.5 \mathrm{wt} \%)$ of benzoxazine surfactant can stabilize water-based epoxy emulsions. The necessary amount of benzoxazine surfactant could be that low that the key film properties of neat epoxy resin, such as cross-linking density, glass transition temperature and hardness, are insignificantly affected. In the next step of the research the lowest concentration of benzoxazine surfactant, which still provides stable emulsions will be determined and the amount of curing agent will be optimized.

\section{Acknowledgements}

The financial support of this work by the Slovenian Ministry of Higher Education, Science and Technology (Grant P2-0191) is gratefully acknowledged. We kindly thank Dr. Branko Alič for ${ }^{1} \mathrm{H}$ NMR spectra analyses.

\section{References}

[1] Holly F. W., Cope A. C.: Condensation products of aldehydes and ketones with o-aminobenzyl alcohol and o-hydroxybenzylamine. Journal of the American Chemical Society, 66, 1875-1879 (1944). DOI: $10.1021 / \mathrm{ja0} 1239 \mathrm{a} 022$

[2] Ishida H., Agag T.: Handbook of benzoxazine resins. Elsevier, Amsterdam (2011).

[3] Nair C. P. R.: Advances in addition-cure phenolic resins. Progress in Polymer Science, 29, 401-498 (2004). DOI: $10.1016 /$ j.progpolymsci.2004.01.004
[4] Ishida H., Allen D. J.: Physical and mechanical characterization of near-zero shrinkage polybenzoxazines. Journal of Polymer Science Part B: Polymer Physics, 34, 1019-1030 (1996).

DOI: 10.1002/(SICI)1099-0488(19960430)34:6<1019 $\because$ AID-POLB1>3.0.CO;2-T

[5] Ghosh N. N., Kiskan B., Yagci Y.: Polybenzoxazines New high performance thermosetting resins: Synthesis and properties. Progress in Polymer Science, 32, 1344 1391 (2007).

DOI: 10.1016/j.progpolymsci.2007.07.002

[6] Yagci Y., Kiskan B., Ghosh N. N.: Recent advancement on polybenzoxazine - A newly developed high performance thermoset. Journal of Polymer Science Part A: Polymer Chemistry, 47, 5565-5576 (2009). DOI: $10.1002 /$ pola.23597

[7] Takeichi T., Kano T., Agag T.: Synthesis and thermal cure of high molecular weight polybenzoxazine precursors and the properties of the thermosets. Polymer, 46, 12172-12180 (2005).

DOI: $10.1016 /$ j.polymer.2005.10.088

[8] Ishida H., Allen D. J.: Mechanical characterization of copolymers based on benzoxazine and epoxy. Polymer, 37, 4487-4495 (1996).

DOI: 10.1016/0032-3861(96)00303-5

[9] Chernykh A., Agag T., Ishida H.: Novel benzoxazine monomer containing diacetylene linkage: An approach to benzoxazine thermosets with low polymerization temperature without added initiators or catalysts. Polymer, 50, 3153-3157 (2009).

DOI: $10.1016 /$ j.polymer.2009.04.061

[10] Kimura H., Matsumoto A., Ohtsuka K.: Studies on new type of phenolic resin - Curing reaction of bisphenolA-based benzoxazine with epoxy resin using latent curing agent and the properties of the cured resin. Journal of Applied Polymer Science, 109, 1248-1256 (2008). DOI: $10.1002 / \mathrm{app} .28279$

[11] Kimura H., Matsumoto A., Hasegawa K., Ohtsuka K., Fukuda A.: Epoxy resin cured by bisphenol A based benzoxazine. Journal of Applied Polymer Science, 68, 1903-1910 (1998).

DOI: $10.1002 /($ sici)1097-4628(19980620)68:12<1903 ::aid-app2>3.0.co;2-p

[12] Rimdusit S., Pirstpindvong S., Tanthapanichakoon W., Damrongsakkul S.: Toughening of polybenzoxazine by alloying with urethane prepolymer and flexible epoxy: A comparative study. Polymer Engineering and Science, 45, 288-296 (2005).

DOI: $10.1002 /$ pen.20273

[13] Kimura H., Matsumoto A., Ohtsuka K.: New type of phenolic resin: Curing reaction of phenol-novolac based benzoxazine with bisoxazoline or epoxy resin using latent curing agent and the properties of the cured resin. Journal of Applied Polymer Science, 112, 17621770 (2009).

DOI: $10.1002 /$ app.29301 
[14] Grishchuk S., Mbhele Z., Schmitt S., Karger-Kocsis J.: Structure, thermal and fracture mechanical properties of benzoxazine-modified amine-cured DGEBA epoxy resins. Express Polymer Letters, 5, 273-282 (2011). DOI: $10.3144 /$ expresspolymlett.2011.27

[15] Grishchuk S., Schmitt S., Vorster O. C., Karger-Kocsis J.: Structure and properties of amine-hardened epoxy/ benzoxazine hybrids: Effect of epoxy resin functionality. Journal of Applied Polymer Science, 124, 28242837 (2012). DOI: $10.1002 / a p p .35302$

[16] Rao B. S., Reddy K. R., Pathak S. K., Pasala A. R.: Benzoxazine-epoxy copolymers: effect of molecular weight and crosslinking on thermal and viscoelastic properties. Polymer International, 54, 1371-1376 (2005).

DOI: $10.1002 /$ pi.1853

[17] Rimdusit S., Kunopast P., Dueramae I.: Thermomechanical properties of arylamine-based benzoxazine resins alloyed with epoxy resin. Polymer Engineering and Science, 51, 1797-1807 (2011).

DOI: $10.1002 /$ pen.21969

[18] Grishchuk S., Sorochynska L., Vorster O. C., KargerKocsis J.: Structure, thermal, and mechanical properties of DDM-hardened epoxy/benzoxazine hybrids: Effects of epoxy resin functionality and ETBN toughening. Journal of Applied Polymer Science, 127, 5082-5093 (2013).

DOI: $10.1002 / a p p .38123$

[19] Kuo S-W., Liu W-C.: Synthesis and characterization of a cured epoxy resin with a benzoxazine monomer containing allyl groups. Journal of Applied Polymer Science, 117, 3121-3127 (2010).

DOI: $10.1002 / a p p .32093$

[20] Sawaryn C., Landfester K., Taden A.: Benzoxazine miniemulsions stabilized with polymerizable nonionic benzoxazine surfactants. Macromolecules, 43, 89338941 (2010).

DOI: $10.1021 / \mathrm{ma101169g}$

[21] Sawaryn C., Landfester K., Taden A.: Benzoxazine miniemulsions stabilized with multifunctional mainchain benzoxazine protective colloids. Macromolecules, 44, 5650-5658 (2011).

DOI: $10.1021 / \mathrm{ma} 200973 \mathrm{~g}$

[22] Chernykh A., Liu J., Ishida H.: Synthesis and properties of a new crosslinkable polymer containing benzoxazine moiety in the main chain. Polymer, 47, 7664-7669 (2006).

DOI: $10.1016 /$ j.polymer.2006.08.041

[23] Choi J-H., Kim H-J.: Three hardness test methods and their relationship on UV-curable epoxy acrylate coatings for wooden flooring systems. Journal of Industrial and Engineering Chemistry, 12, 412-417 (2006).

[24] Griffin W. C.: Calculation of HLB values of non-ionic surfactants. Journal of the Society of Cosmetic Chemists, 5, 249-256 (1954).
[25] Hecht L. L., Schoth A., Muñoz-Espi R., Javadi A., Köhler K., Miller R., Landfester K., Schuchmann H. P.: Determination of the ideal surfactant concentration in miniemulsion polymerization. Macromolecular Chemistry and Physics, 214, 812-823 (2013). DOI: $10.1002 / \mathrm{macp} .201200583$

[26] Landfester K., Bechthold N., Tiarks F., Antonietti M.: Formulation and stability mechanisms of polymerizable miniemulsions. Macromolecules, 32, 5222-5228 (1999). DOI: $10.1021 / \mathrm{ma990299+}$

[27] Landfester K.: Recent developments in miniemulsions - Formation and stability mechanisms. Macromolecular Symposia, 150, 171-178 (2000).

DOI: 10.1002/1521-3900(200002)150:1<171::aid-masy 171>3.0.co;2-d

[28] Ning X., Ishida H.: Phenolic materials via ring-opening polymerization: Synthesis and characterization of bisphenol-A based benzoxazines and their polymers. Journal of Polymer Science Part A: Polymer Chemistry, 32, 1121-1129 (1994). DOI: $10.1002 /$ pola.1994.080320614

[29] Ning X., Ishida H.: Phenolic materials via ring-opening polymerization of benzoxazines: Effect of molecular structure on mechanical and dynamic mechanical properties. Journal of Polymer Science Part B: Polymer Physics, 32, 921-927 (1994). DOI: $10.1002 /$ polb.1994.090320515

[30] Karger-Kocsis J., Grishchuk S., Sorochynska L., Rong M. Z.: Curing, gelling, thermomechanical, and thermal decomposition behaviors of anhydride-cured epoxy (DGEBA)/epoxidized soybean oil compositions. Polymer Engineering and Science, 54, 747-755 (2014). DOI: 10.1002/pen.23605

[31] Chow W. S., Grishchuk S., Burkhart T., Karger-Kocsis J.: Gelling and curing behaviors of benzoxazine/epoxy formulations containing 4,4'-thiodiphenol accelerator. Thermochimica Acta, 543, 172-177 (2012). DOI: $10.1016 /$ j.tca.2012.05.015

[32] Wang H., Zhao P., Ling H., Ran Q., Gu Y.: The effect of curing cycles on curing reactions and properties of a ternary system based on benzoxazine, epoxy resin, and imidazole. Journal of Applied Polymer Science, 127, 2169-2175 (2013).

DOI: $10.1002 / a p p .37778$

[33] Wirasate S., Dhumrongvaraporn S., Allen D. J., Ishida H.: Molecular origin of unusual physical and mechanical properties in novel phenolic materials based on benzoxazine chemistry. Journal of Applied Polymer Science, 70, 1299-1306 (1998).

DOI: 10.1002/(sici)1097-4628(19981114)70:7<1299:: aid-app6>3.3.co;2-b

[34] Kim H-D., Ishida H.: Study on the chemical stability of benzoxazine-based phenolic resins in carboxylic acids. Journal of Applied Polymer Science, 79, $1207-$ 1219 (2001).

DOI: $10.1002 / 1097-4628(20010214) 79: 7<1207::$ aidapp80>3.0.co;2-3 